\title{
Cerium Oxyhydroxide Nanowire Growth via Electrogeneration of Base in Nonaqueous Electrolytes
}

\author{
Patrizia Bocchetta, ${ }^{\mathrm{z}}$ Monica Santamaria, ${ }^{*}$ and Francesco Di Quarto* \\ Dipartimento di Ingegneria Chimica dei Processi e dei Materiali, Università di Palermo,
}

Viale delle Scienze, 90128 Palermo, Italy

The preparation of compact cerium oxyhydroxide nanowires into anodic alumina membranes from cerium chloride in ethanol solution via electrogeneration of base is reported. Scanning electron microscopy analyses indicate that dense, well-aligned, and highly ordered nanowires can be formed in a wide range of applied potentials and current densities in alcoholic solution. The employment of water brings to a hybrid nanotube/nanowire structure, suggesting a key role of the electrolyte nature in determining the morphology of the deposit. Electrochemical findings and X-ray diffraction analysis have shown that nanowires are constituted by a $\mathrm{Ce}(\mathrm{III}) / \mathrm{Ce}(\mathrm{IV})$ oxyhydroxide that can be completely oxidized into $\mathrm{CeO}_{2}$ by thermal treatment.

(C) 2008 The Electrochemical Society. [DOI: 10.1149/1.2953230] All rights reserved.

Manuscript submitted April 24, 2008; revised manuscript received June 11, 2008. Published July 11, 2008.

Ceria-based solid electrolytes are the most promising alternative of yttria-stabilized zirconia as a fast ionic conductor for solid oxide fuel cells (SOFCs) with the advantage of a lower operating temperature. ${ }^{1-3}$ In a previous work we have reported the synthesis of cerium oxyhydroxide nanotubes (NTs) via electrogeneration of base in aqueous solution using anodic alumina (AAM) as a template. ${ }^{4}$ Even if ceria NTs present various interesting applications related to their high surface area, they are not suitable to be used as SOFC solid electrolyte due to their hollow interiors. It has been demonstrated in previous works that porous anodic alumina can be successfully employed as an ionic conductor support in fuel cells due to their physicochemical properties. ${ }^{5,6}$ AAMs have a high thermal stability that prevents the powdering of the ionic conductor with possible gas crossover or short circuit problems. Moreover, alumina membranes show an extremely ordered porous structure with an easy electrochemical control of thickness (from a few micrometers to hundreds of micrometers), porosity (from 10 to $43 \%$ ), and pore diameter (20-200 nm), which guarantee a highly precise control of the size of the ionic nanowire conductor. This aspect is very important if we take into account that the performances of solid electrolyte fuel cells are mainly controlled by the ohmic drop into the electrolyte, which in turn depends on the thickness of the ionic conductor. $^{7,8}$ The problem of a complete nanopore filling with solid ionic conductor is actually a critical step, so the possibility of finding the experimental conditions allowing direct electrodeposition of ceria nanowires into a ceramic host material, such as AAM, is very appealing.

In this work we have successfully investigated the possibility of preparing high-quality cerium oxyhydroxide nanowires (NWs) into porous AAMs via electrogeneration of base. ${ }^{9-13}$ The electrochemical process was performed in a $0.3 \mathrm{M} \mathrm{CeCl}_{3} \cdot 7 \mathrm{H}_{2} \mathrm{O}$ in ethanol electrolyte, where the electrodeposition of compact, resistant, and adherent film of cerium oxyhydroxide on flat substrates is reported to occur. ${ }^{14-16}$ The influence of the electrochemical parameters on the composition and morphology of the grown nanostructures was studied in order to elucidate the possible mechanism operating during the deposition. Finally, it was studied whether a thermal treatment of the as-deposited cerium oxyhydroxide NW/AAM composites allow the complete oxidation of $\mathrm{Ce}(\mathrm{III})$ to $\mathrm{Ce}(\mathrm{IV})$ without any modification of the morphological aspect.

\section{Experimental}

Commercial AAMs (Whatman, average pore diameter $200 \mathrm{~nm}$, porosity $43 \%$ ) were employed as a template. Gold was sputtered on one side of the membrane to serve as a conductive layer. AAM/Au electrodes were electrically connected with an aluminum disk using

\footnotetext{
* Electrochemical Society Active Member.

${ }^{\mathrm{z}}$ E-mail: bocchetta@dicpm.unipa.it
}

a silver paste. Different active surface areas were exposed to the solution by using a holder with silicon gaskets $\left(S=2.54 \mathrm{~cm}^{2}\right)$ or an insulating lacquer (Lacomit Stopping-off, U.K.) $\left(S=1 \mathrm{~cm}^{2}\right)$. The $\mathrm{AAM} / \mathrm{Au}$ electrode assemblies were kept in the growth electrolyte for $2 \mathrm{~h}$ before starting the electrodeposition in order to fill the porous structure of the template with the solution. The electrodeposition process was carried out in a fresh ethyl alcohol $0.3 \mathrm{M} \mathrm{CeCl}_{3} \cdot 7 \mathrm{H}_{2} \mathrm{O}$ solution, prepared by stirring overnight at room temperature. A classic three-electrode cell was employed with the AAM/Au as working electrode, a graphite electrode as counter electrode, and a saturated calomel electrode (SCE) as reference electrode connected to the cell through a salt bridge. The anodic and cathodic compartments were separated by a sintered glass disk. The cathodic polarization was performed at room temperature in potentiostatic (from $-3 \mathrm{~V} / \mathrm{SCE}$ to $-9 \mathrm{~V} / \mathrm{SCE}$ ) and amperostatic regime (from $0.3 \mathrm{~mA} / \mathrm{cm}^{-2}$ to $4 \mathrm{~mA} / \mathrm{cm}^{2}$ ) for a variable deposition time by using an EG\&EG potentiostat (Princeton Applied Research) model 173, a multichannel potentiostat VMP2 (Princeton Applied Research), and a Keithley current source model 227. Thermal treatment of AAM/NWs samples was realized in an oven at $500^{\circ} \mathrm{C}$ in air.

Morphology and quality of the NWs were investigated by using a Philips XL30 ESEM scanning electron microscope (SEM). The AAM/NW samples were chemically etched in $1 \mathrm{M} \mathrm{NaOH}$ for $2 \mathrm{~h}$ in order to remove the alumina host, and successively washed in $\mathrm{H}_{2} \mathrm{O}$ and filtered, producing numerous pieces of random broken NW arrays on the stub. X-ray analysis of composite AAM/ NW arrays was realized by a Philips X-ray generator (model PW 1130) and a PW (model 1050) goniometry. All diffractograms have been obtained in the $2 \theta$ range from 10 to $100^{\circ}$ with a step of $0.02^{\circ}$ and a measuring time of $0.5 \mathrm{~s}$ for step using copper $\mathrm{K} \alpha$ radiation $(\lambda=1.54 \mathrm{~A})$. The identification was performed according to the International Centre for Diffraction Data (ICDD) available cards.

\section{Results and Discussion}

Electrochemical studies. - In Fig. 1a we report the current density vs time curve recorded by polarizing at constant voltage, $U_{\mathrm{E}}$ $=-3 \mathrm{~V}$, the $\mathrm{AAM} / \mathrm{Au}$ in $0.3 \mathrm{M} \mathrm{CeCl}_{3} \cdot 7 \mathrm{H}_{2} \mathrm{O}$ in ethanol electrolyte. The measured cathodic current density can be associated to reduction processes involving water (introduced into the electrolyte as cerium chloride hydration water with $\mathrm{Ce} / \mathrm{H}_{2} \mathrm{O}=1 / 7$ ) and/or oxygen (dissolved into the electrolyte) according to the following halfcell reactions

$$
\begin{aligned}
& 2 \mathrm{H}_{2} \mathrm{O}+2 \mathrm{e}^{-} \rightarrow \mathrm{H}_{2}+2 \mathrm{OH}^{-} \\
& \mathrm{O}_{2}+2 \mathrm{H}_{2} \mathrm{O}+4 \mathrm{e}^{-} \rightarrow 4 \mathrm{OH}^{-}
\end{aligned}
$$

These reactions bring both the formation of $\mathrm{OH}^{-}$reacting with $\mathrm{Ce}^{3+}$ and subsequent $\mathrm{Ce}(\mathrm{OH})_{3}$ precipitation. Due to the presence of $\mathrm{O}_{2}$, the formation of $\mathrm{CeO}_{2}$ can also occur according to the following equation [Ref. 4 and references therein] 

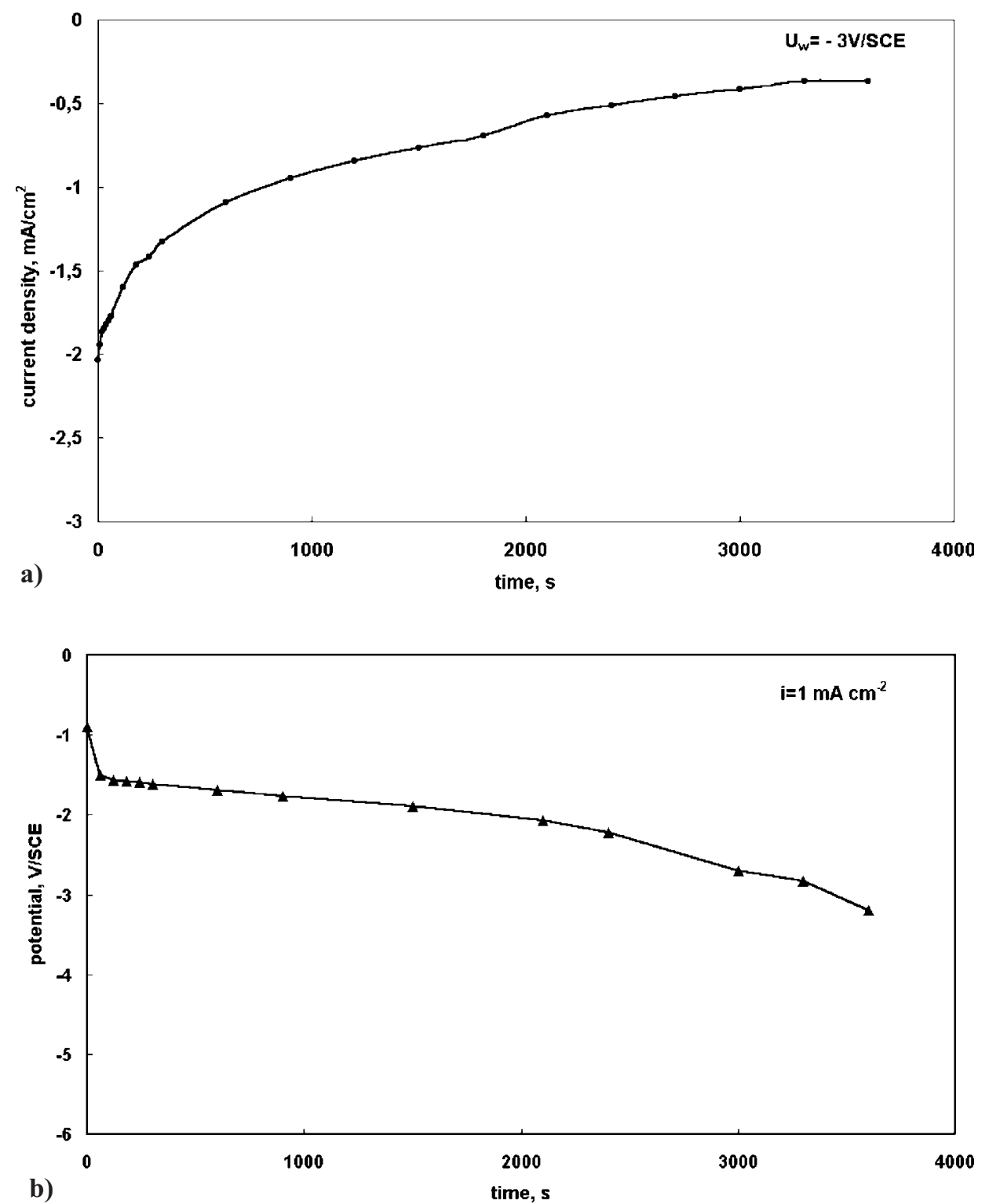

Figure 1. Deposition curves during the electrodeposition of $\mathrm{Ce}$ oxyhydroxide NWs inside porous AAM in $0.3 \mathrm{M} \mathrm{CeCl}_{3} \cdot 7 \mathrm{H}_{2} \mathrm{O}$ in ethanol solution. (a) Current density vs time at $-3 \mathrm{~V} / \mathrm{SCE}$. (b) Potential (ref. SCE) vs time at $i$ $=1 \mathrm{~mA} / \mathrm{cm}^{2}$.

$$
2 \mathrm{Ce}^{3+}+4 \mathrm{OH}^{-}+\mathrm{O}_{2}+2 \mathrm{e}^{-} \rightarrow 2 \mathrm{CeO}_{2}+2 \mathrm{H}_{2} \mathrm{O}
$$

Due to the high cathodic potential applied during the deposition, we cannot exclude that the reduction process can involve the solvent, which can be reduced to methane with $\mathrm{OH}^{-}$production

$$
\mathrm{CH}_{3} \mathrm{CH}_{2} \mathrm{OH}+3 \mathrm{H}_{2} \mathrm{O}+4 \mathrm{e}^{-} \rightarrow 2 \mathrm{CH}_{4}+4 \mathrm{OH}^{-}
$$

The electroreduction of ethanol to ethane or methane in aqueous electrolyte is reported to occur at potential more anodic with respect to those applied in potentiostatic experiments or measured in this work in the case of galvanostatic deposition. ${ }^{17}$

Equations $1 \mathrm{a}$ and 2 can explain the gas evolution observed during the electrochemical process. At constant applied potential, in the exploited potential range $\left(-9 \leq U_{\mathrm{E}} \leq-3 \mathrm{~V}\right)$ the current decreases with increasing time. In order to explain such dependence it is useful to describe the applied potential difference, $\Delta \Phi_{\text {Au-el }}$, between the Au metallic contact on the electrode and the bulk of the electrolyte, to which the reference electrode is short-circuited by the salt bridge, as follows

$$
\Delta \Phi_{\mathrm{Au}-\mathrm{el}}=\Delta \Phi_{\mathrm{Au}-\mathrm{nw}}+\Delta \Phi_{\mathrm{nw}-\mathrm{el}}
$$

where $\Delta \Phi_{\text {Au-nw }}$ represents the potential drop between the gold and the electrolyte solution at the surface of the growing NWs, and
$\Delta \Phi_{\text {nw-el }}$ is the potential drop between the NWs growing front and the bulk of the electrolyte. $\Delta \Phi_{\mathrm{Au}-\mathrm{nw}}$ is expected to increase by increasing the NW length, i.e., the deposition time, while $\Delta \Phi_{\text {nw-el }}$ has to decrease in order to keep $\Delta \Phi_{\text {Au-el }}$ constant. Because $\Delta \Phi_{\text {nw-el }}$ is the true driving force for the electrochemical process, a decreasing reaction rate (i.e., current density) is predicted with increasing deposition time.

To further investigate the effect of the electrodeposition conditions on the structure of the deposits, we also performed galvanostatic depositions in a wide current density range $\left(0.3-4 \mathrm{~mA} / \mathrm{cm}^{-2}\right)$. In Fig. 1b we report the dependence of the working electrode potential as a function of time recorded during a galvanostatic deposition at $1 \mathrm{~mA} \mathrm{~cm}{ }^{-2}$. The potential of the working electrode (AAM/ $\mathrm{Au}$ ) increases in the cathodic direction in order to sustain a constant current density accompanied by the growing of the deposit thickness (i.e. NW length, see Fig. 2 and 3).

The whole description of the electrochemical process involves an electrochemical reaction front moving toward the bulk of the solution with increasing deposition time, in agreement with the formation of NWs inside the pores of AAMs.

Morphological investigation.- A detailed morphological analysis of the cerium oxyhydroxide deposits as-prepared and after re- 


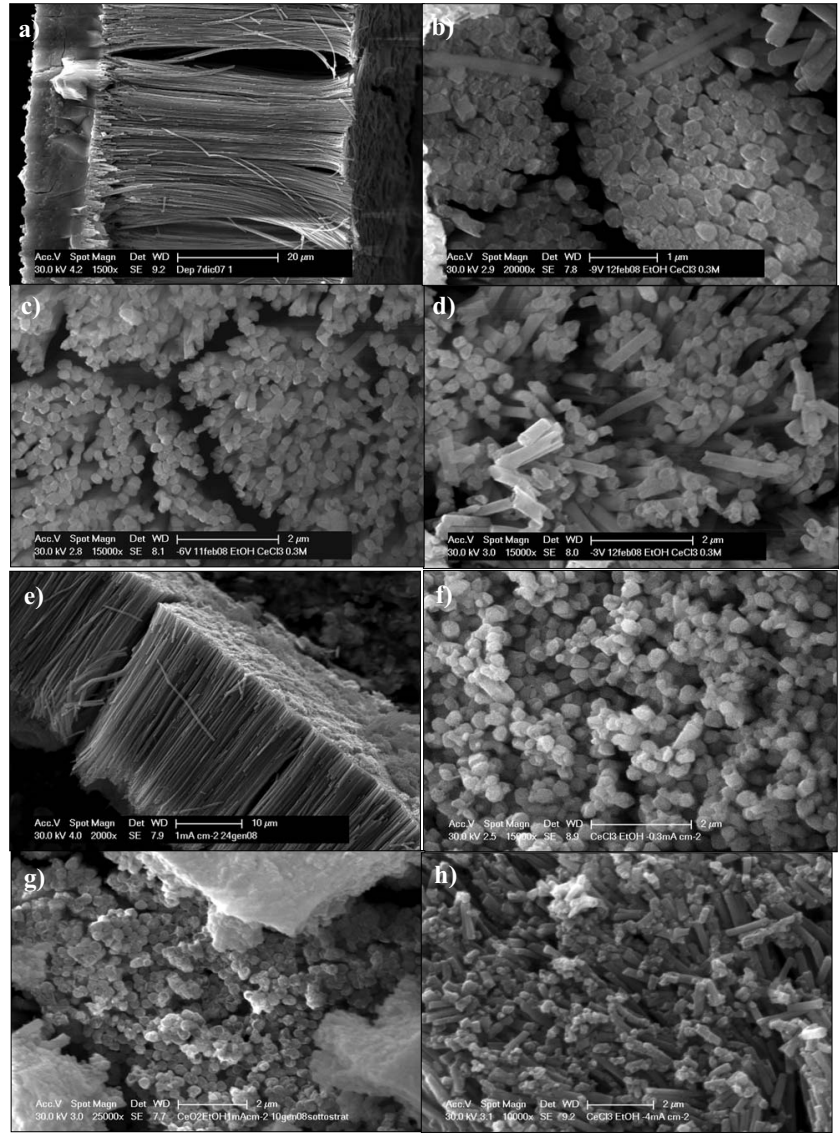

Figure 2. SEM images of freestanding Ce oxyhydroxide NWs after removal of the alumina template by chemical etching in $1 \mathrm{M} \mathrm{NaOH}$ solution at different electrodeposition conditions in $0.3 \mathrm{M} \mathrm{CeCl}_{3} \cdot 7 \mathrm{H}_{2} \mathrm{O}$ in ethanol solution for $1 \mathrm{~h}$. (a) Side view of sample prepared at -9 V/SCE. Surface morphology of samples prepared at (b) -9 , (c) -6 , and (d) -3 V/SCE. (e) Side view of sample prepared at $i=1 \mathrm{~mA} / \mathrm{cm}^{2}$. Surface morphology of sample prepared at (f) $i=0.3,(\mathrm{~g}) i=1$, and (h) $i=4 \mathrm{~mA} / \mathrm{cm}^{2}$.

moval of the AAM template by etching in $1 \mathrm{M} \mathrm{NaOH}$ was performed over several randomly broken nanostructures. As shown in Fig. 2, the SEM examinations revealed a NW-type morphology for all the electrodeposits prepared at different applied potentials $(-3$, -6 , and $-9 \mathrm{~V} / \mathrm{SCE})$ and current densities $\left(0.3,1,4 \mathrm{~mA} / \mathrm{cm}^{-2}\right)$. The NWs show compact, continuous, and perfectly cylindrical morphology, replicating the highly ordered parallelism of the template porous structure. This result suggests that in $\mathrm{CeCl}_{3} /$ ethanol electrolyte the cerium oxyhydroxide electroprecipitation is driven toward the $\mathrm{NW}$ formation through a mechanism independent of the electrical parameters chosen to perform the electrochemical process. In a previous work we have reported the formation of cerium oxyhydroxide NTs via electrogeneration of base from a $\mathrm{Ce}\left(\mathrm{NO}_{3}\right)_{3}$ aqueous electrolyte. The simple replacement of cerium nitrate by cerium chloride in water did not allow to obtain uniform arrays of NWs (see Fig. 3a) due to the formation of a hybrid structure of NWs and NTs in a wide current density range (from $5 \mu \mathrm{A} / \mathrm{cm}^{-2}$ to $4 \mathrm{~mA} / \mathrm{cm}^{-2}$ ).

The formation of NWs instead of NTs in $\mathrm{CeCl}_{3} /$ alcohol ethylic solution can be related to the reported tendency of this electrolytic solution to favor the formation of compact and dense electrodeposition product via electrogeneration of base on flat geometry. According to Ref. 15, the addition of ethyl alcohol into an aqueous electrolyte reduces the total dielectric constant of solvent and, thus, the solubility of the deposit. The overall effect is to promote particle coagulation and gel formation, leading to homogeneous and continuous coatings with reduced cracked areas and porosity. Moreover,

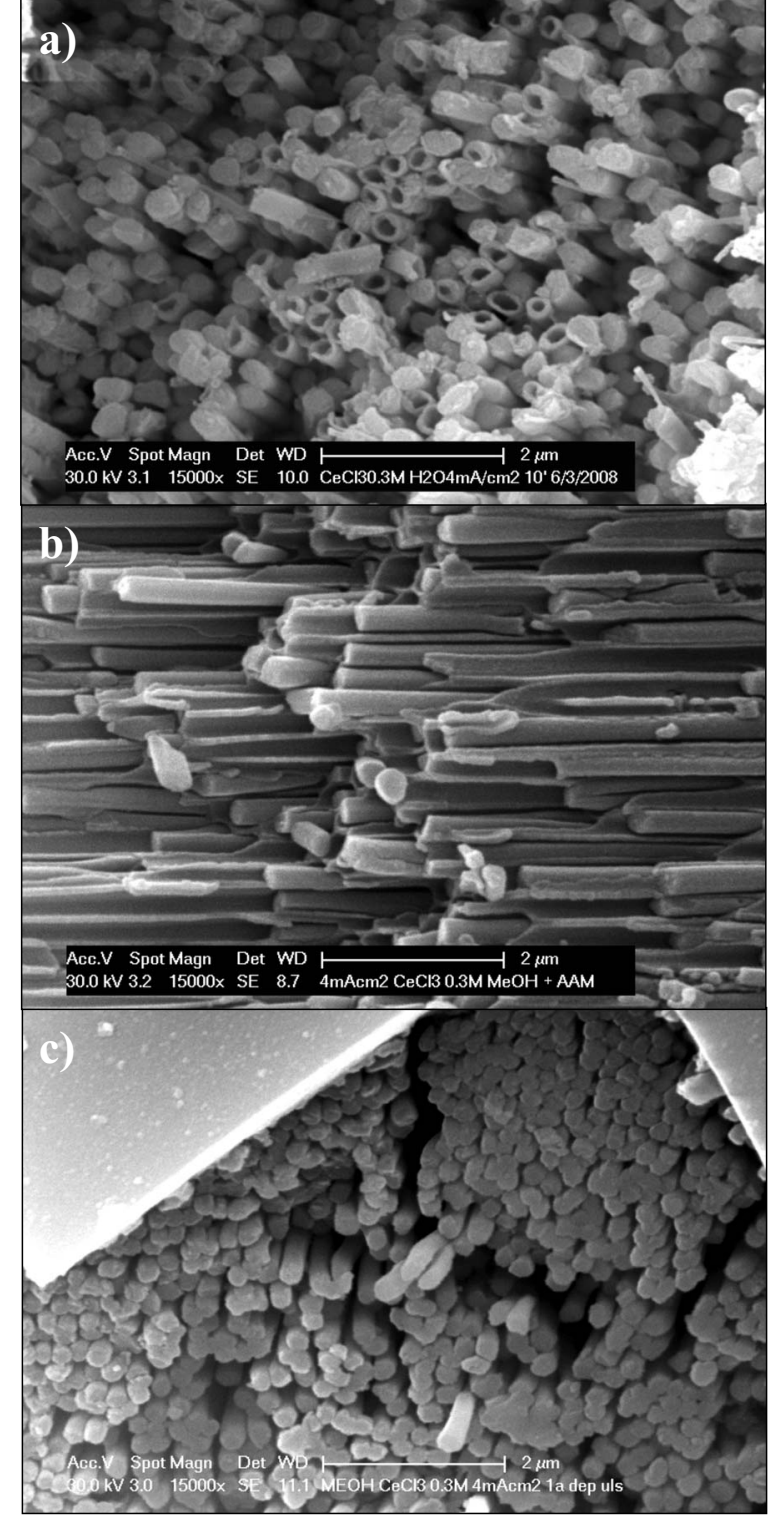

Figure 3. SEM images of Ce oxyhydroxide nanostructures electrodeposited at $i=4 \mathrm{~mA} / \mathrm{cm}^{2}$ in $0.3 \mathrm{M} \mathrm{CeCl}_{3} \cdot 7 \mathrm{H}_{2} \mathrm{O}$ for $1 \mathrm{~h}$ from (a) aqueous and (b, c) methanol solution. (a) Hybrid structure NWs/NTs prepared in aqueous solution after removal of the alumina template. (b) Side view of NWs into alumina template and (c) surface morphology of template-free Ce oxyhydroxide NWs electrodeposited from methanol solution.

in Ref. 16 it is indicated that ceria deposits obtained from $\mathrm{CeCl}_{3}$ solutions are more adherent and uniform than with other salts.

The role of the solvent properties in determining the kind of nanostructure morphology is further confirmed by performing the electrodeposition in a $\mathrm{CeCl}_{3} \cdot 7 \mathrm{H}_{2} \mathrm{O}$ containing solution employing an amphiprotic solvent with dielectric constant close to that of ethanol, i.e., methanol. As shown in Fig. $3 b$ and c, dense and continuous NWs grow in this electrolyte with morphology very similar to those grown in ethanol solution. The AAM free nanostructures are mechanically resistant, even after etching in $1 \mathrm{M} \mathrm{NaOH}$, washing in $\mathrm{H}_{2} \mathrm{O}$, and filtering (see Fig. 2 and 3). SEM investigations on thermal-treated samples indicate that the AAM-free NWs maintain their integrity and parallelism after the thermal oxidation, as shown in Fig. 4, where the side views of NWs prepared at $4 \mathrm{~mA} / \mathrm{cm}^{-2}$ in $0.3 \mathrm{M} \mathrm{CeCl}_{3} \cdot 7 \mathrm{H}_{2} \mathrm{O}$ as-prepared and after thermal treatment $(4 \mathrm{~h}$ at $500^{\circ} \mathrm{C}$ ) are compared. 


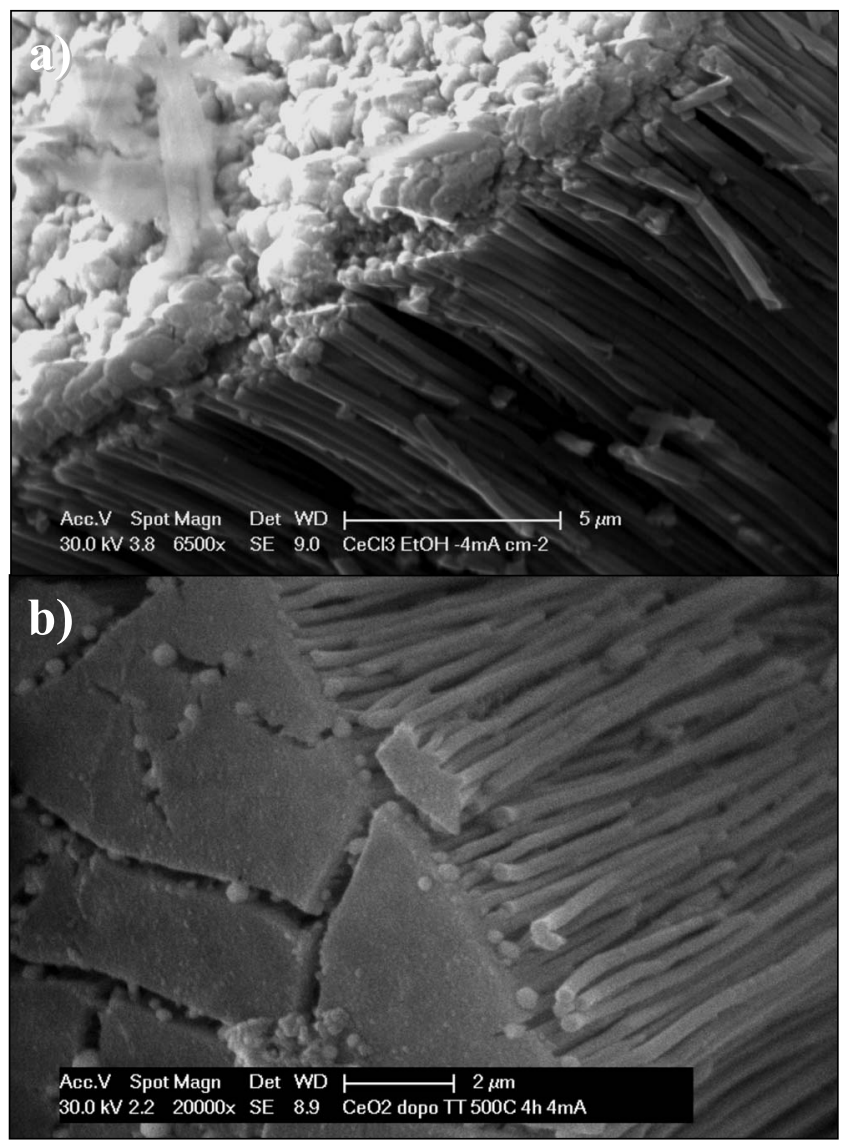

Figure 4. Side view of freestanding Ce oxyhydroxide NWs after removal of the alumina template electrodeposited at $i=4 \mathrm{~mA} / \mathrm{cm}^{2}$ in $0.3 \mathrm{M} \mathrm{CeCl} \cdot 7 \mathrm{H}_{2} \mathrm{O}$ ethanol solution (a) as-prepared and (b) after thermal treatment $\left(4 \mathrm{~h}\right.$ at $500^{\circ} \mathrm{C}$ in air).

Structural analysis. - X-ray diffraction (XRD) analysis of AAM/electrodeposits soon after preparation in all the investigated experimental conditions revealed the presence of broad and not pronounced peaks due to a scarce crystallinity of the NWs and/or to the presence of the AAM host. The peaks were attributed to $\mathrm{Ce}(\mathrm{OH})_{3}$ (ICCD card 74-0665), $\mathrm{Ce}_{2} \mathrm{O}_{3}$ (ICCD card 23-1048), and $\mathrm{CeO}_{2}$ (ICCD cards 34-0394 and 01-0880) in accordance with our previous findings in aqueous solution. ${ }^{4}$ Moreover, these results are consistent with the compositional analysis performed on films electrodeposited from $0.3 \mathrm{M} \mathrm{CeCl}_{3} \cdot 7 \mathrm{H}_{2} \mathrm{O}$ in naturally aerated ethanol solution reported in Ref. 18, where X-ray photoelectron spectroscopic well-pronounced peaks characteristic of $\mathrm{Ce}(\mathrm{III})$ and weak features of $\mathrm{Ce}(\mathrm{IV})$ are evidenced.

In Fig. 5 we report the XRD patterns of $\mathrm{AAM} / \mathrm{NWs}$ prepared at $4 \mathrm{~mA} / \mathrm{cm}^{2}$ in $0.3 \mathrm{M} \mathrm{CeCl}_{3} \cdot 7 \mathrm{H}_{2} \mathrm{O}-\mathrm{EtOH}$ solution and different circulated charges, before and after the thermal treatment. The main peak relating to $\mathrm{CeO}_{2}\left(2 \theta=28.55^{\circ}\right)$ is evident only when the resulting charge per unit area is high enough to allow the growth of a cerium-containing deposit ( $\sim 10$ to $15 \mu \mathrm{m}$ thick) out of the alumina template, as revealed by SEM (see Fig. 2a). The AAM-free layer, grown in a more aerated solution with respect to the deposit inside the membrane pores, is richer in $\mathrm{Ce}$ (IV) with respect to NWs, as expected on the base of Eq. 1c. According to the XRD analysis, thermal treatments $\left(4 \mathrm{~h}\right.$ at $500^{\circ} \mathrm{C}$ under air exposure) of AAM/NW samples without a compact layer induce the complete oxidation of $\mathrm{Ce}(\mathrm{OH})_{3}$ to $\mathrm{CeO}_{2}$ and improve the crystallinity of the deposited materials (see Fig. 5).

\section{Conclusions}

In this work, by exploiting the synergic properties of alcoholic solvent and $\mathrm{CeCl}_{3}$ solute, the electrochemical preparation of compact cerium oxyhydroxide NWs into anodic alumina membranes is reported. A mechanism of electrogeneration of base is suggested to occur during the deposition, in agreement with previous findings in aqueous solution. ${ }^{4}$

SEM investigations performed over numerous samples indicate that dense, well-aligned, and highly ordered NWs can be produced from a $\mathrm{CeCl}_{3}$-containing alcoholic solution in a wide range of applied potentials and current densities, suggesting a key role of the electrolyte nature in determining the morphology of the nanostructures.

Electrochemical findings and XRD analysis have shown that NWs are mainly constituted by a Ce(III) hydroxide, while the formation of $\mathrm{CeO}_{2}$ seems to occur when the pore filling is complete and a compact layer is formed on the AAM template.

Thermal treatment at $500^{\circ} \mathrm{C}$ in oxygen atmosphere of the AAM/ nanostructure composite allows production of $\mathrm{CeO}_{2} \mathrm{NWs}$ without

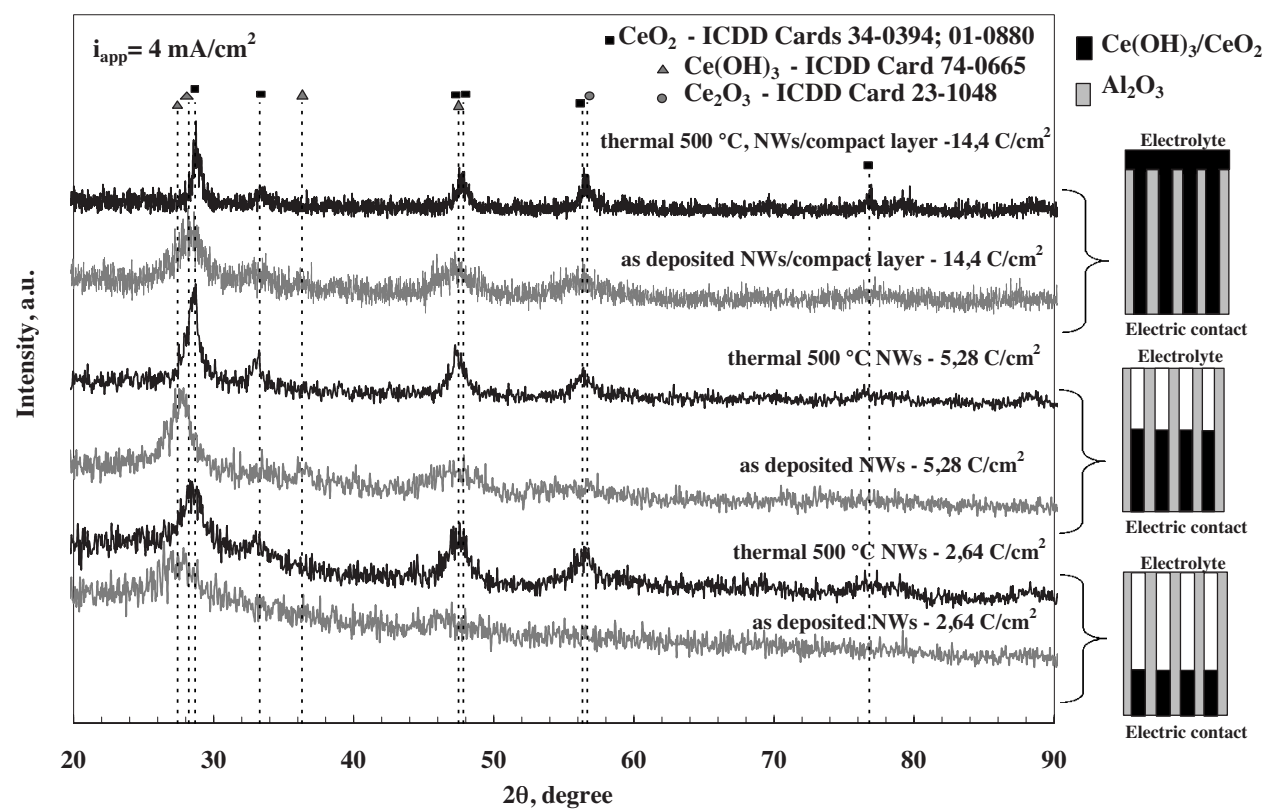

Figure 5. X-ray diffractograms of AAM/ NWs prepared at $4 \mathrm{~mA} / \mathrm{cm}^{2}$ in $0.3 \mathrm{M} \mathrm{CeCl}_{3} \cdot 7 \mathrm{H}_{2} \mathrm{O}$ ethanol solution asprepared and after thermal treatment $(4 \mathrm{~h}$ at $500^{\circ} \mathrm{C}$ ) at different circulated charges. 
any appreciable influence on their integrity and on their morphology. It appears that the electrochemical technique can be a powerful tool for the fabrication of thin-film ionic conductor to be used in solid oxide fuel cells.

\section{Acknowledgments}

This work was sponsored by USAITC-A under contract no. W911NF-07-1-0564 and University of Palermo. One of the authors (P.B.) gratefully thanks Regione Sicilia (Program APQ Ricerca "Laboratorio dell'innovazione nel settore dei beni culturali"- delibera CIPE no.17/2003) for providing a fellowship.

University of Palermo assisted in meeting the publication costs of this article.

\section{References}

1. I. Riess, M. Godickemeier, and L. J. Glaucker, Solid State Ionics, 90, 91 (1996)

2. M. Godickemeier and L. J. Gauckler, J. Electrochem. Soc., 145, 414 (1998).

3. B. C. H. Steele, Solid State Ionics, 129, 95 (2000).

4. P. Bocchetta, M. Santamaria, and F. Di Quarto, Electrochem. Solid-State Lett., 11, K27 (2008).
5. G. P. Chiavarotti, C. Sunseri, U. Gullo, F. Di Quarto, and P. Bocchetta, European Pat. Appl. EP 1357626 A1 (2003) and EP 1391235 A2 (2004).

6. P. Bocchetta, F. Conciauro, and F. Di Quarto, J. Solid State Electrochem., 11, 1253 (2007).

7. S. M. Haile, D. A. Boysen, C. R. I. Chisholm, and R. B. Merle, Nature (London), 410, 910 (2001).

8. P. Bocchetta, G. P. Chiavarotti, R. Masi, C. Sunseri, and F. Di Quarto, Electrochem. Commun., 6, 923 (2004)

9. M. Nobial, O. Devos, O. R. Mattos, and B. Tribollet, J. Electroanal. Chem., 600 , 87 (2007).

10. G. H. A. Therese and P. V. Kamath, Chem. Mater, 12, 1195 (2000).

11. P. Bocchetta, M. Santamaria, and F. Di Quarto, Electrochem. Commun., 9, 683 (2007).

12. M. Lai, J. A. G. Martinez, M. Grätzel, and D. J. Riley, J. Mater. Chem., 16, 2843 (2006).

13. J. Oh, Y. Tak, and J. Lee, Electrochem. Solid-State Lett., 7, C27 (2004).

14. I. Zhitomirsky and A. Petric, Ceram. Int., 27, 149 (2001).

15. I. Zhitomirsky, Adv. Colloid Interface Sci., 97, 277 (2002).

16. I. Zhitomirsky and A. Petric, Mater. Lett., 40, 263 (1999).

17. V. M. Schmidt, R. Ianniello, E. Pastor, and S. Gonzáles, J. Phys. Chem., 100, 17901 (1996).

18. P. Stefanov, G. Atanasova, D. Stoychev, and Ts. Marinova, Surf. Coat. Technol., 180-181, 446 (2004). 